\title{
AN ANALYSIS OF GEOLOGICAL TEXTBOOKS, AT 1830-1930
}

\author{
Makri K. ${ }^{1}$, Pavlides S.B. ${ }^{1}$, Kastanis N. ${ }^{2}$ \\ ${ }^{1}$ Department of Geology, Aristotle University of Thessaloniki,kmakri@geo.auth.gr,pavlides@geo.auth.gr \\ ${ }^{2}$ Department of Mathematics, Aristotle University of Thessaloniki, nioka@math.auth.gr
}

\begin{abstract}
The geological education in Greece is essentially rooted in the second half of the 19th century. Since 1836, when the Secondary Education was legislated in Greece, in spite of the fact that Geology is referred to all educational programs, geology was not taught before 1880, due to the lack of competent teachers and their books. The deficiency is limited with the first complete edition of the book Geology addressed in Secondary Education. This work presents and analyzes the content of a representative sample of school textbooks of Geology, as the approach of geological theories, including the definition and interpretation of geological phenomena, is the result of the trend, followed by each author.
\end{abstract}

Key words: Secondary Education. geological text books.

\section{Introduction}

The analysis of school textbooks is based on registering differences, identifying patterns and making comparisons. In this paper, an attempt for the comparison of geological textbooks in Greece is presented. At the present work, two books that were taught at the Secondary Education, "Physical Political Geography" by Con. Mitsopoulos and "Elements of Geology" by Anastasios Megas, and two books that were used at the University of Athens, during the above period, "Elements of Geology" by Con.Mitsopoulos, at 1885, and "Elements of Geology" by the same author, at 1893, are studied. A basic criterion on the selection of the above textbooks is the fact that they were approved by the Ministry of Ecclesiastical Affairs and Public Education, as well as the recognition of their authors. The above academic books are the first complete Greek ones, whose author wrote one of the presented textbooks.

By the comparison of the above books, comments are generated about their compatibility and the uniformity of the level of Geology in Secondary and Academic Education at the University of Athens. The implementation of Geology in Secondary and Academic Education is conducted almost simultaneously, but with significant differences in the content.

\section{Geological textbooks}

The used school textbooks belong to different time periods from 1885 until 1922. There is no information on the origin and the influences of the books "Elements of Geology" by A. Megas and "Physical and Political Geography" by Con. Mistopoulos. However, it is noted that there is extended literature, mainly German as well as English, French and Italian, at the academic book of the same period, written by the last mentioned author. 


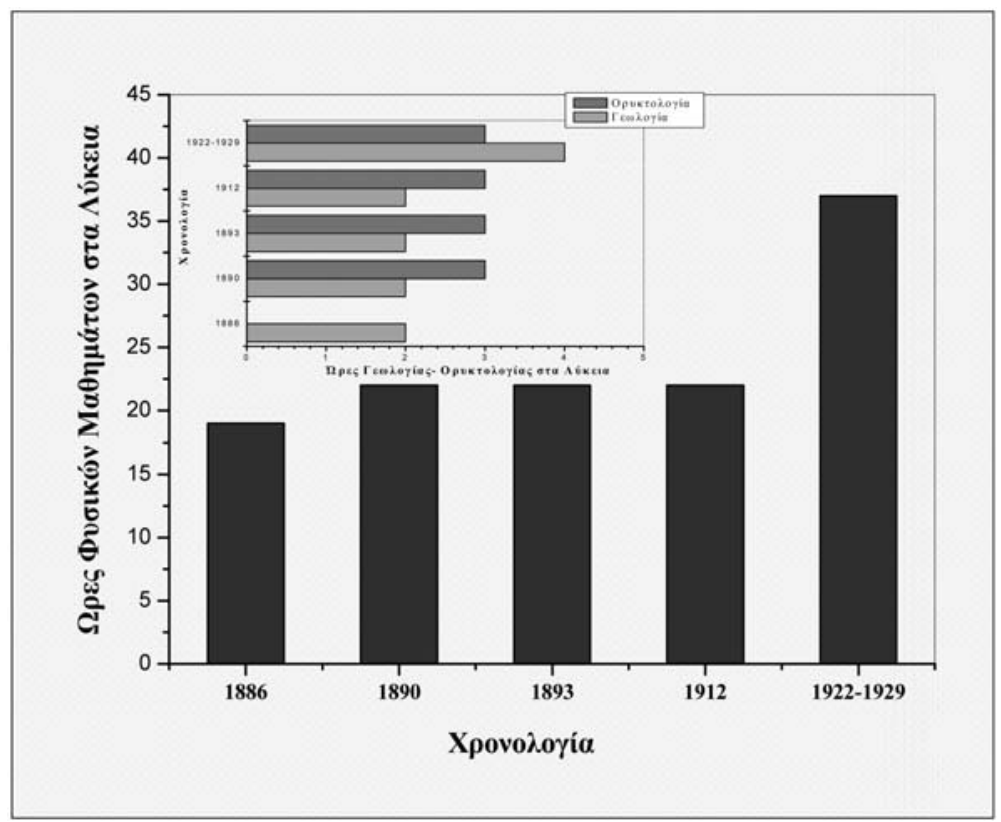

Fig. 1: Development of Natural Sciences in Practical Lyceum (Makri, 2006).

\subsection{The appearance of geological education}

Since 1836 when the Secondary Education is legislated in Greece, the teaching of Geology is present in all educational programs. Essentially, however, Geology is not taught systematically, due to the lack of competent teachers and validly authorized books. Since 1880, due to the approval of textbooks on Geology by the Ministry of Education, the systematic teaching of Geology is observed, leading to the authorship of new geological textbooks. (Fig. 1).

At the University of Athens, since its establishment in 1839, the seat of Natural History on the subjects Zoology, Mineralogy, Geology and Botany is included at the permanent regular seats. At the schedule study at the University of Athens (Historical Archives of University of Athens) since 1864 and until 1911, it is clear that geology was taught daily, while Mineralogy was taught three days per week. Hercules Mitsopoulos (Patras, 1816 - Athens 1892) was the first teacher of Geology until 1890, where he was succeeded by his nephew Constantine Mitsopoulos (Patras, 1846 - Athens, 1911).

\subsection{Textbooks of University Education}

Con. Mitsopoulos, in his book Elements of Geology of 1893, cites literature in the preface, mainly from German and English books, by distinguished scientists such as Ch. Lyell, J. Schmidt, and J. Dana (Fig. 2). The self-titled book published in 1885, which is lithograph, the style of content varies slightly from the version of 1893. In particular, the issue of 1893 contained more detailed topics on tectonic structures and seismology. Throughout the book, a narrative structure for natural science subjects, in general, dominates. At the chapter on the utility of Geology, Con. Mitsopoulos refers that peculiar interpretations on Geological phenomena have been attributed at different periods, because Church Authorities did not allow subversive theories and 


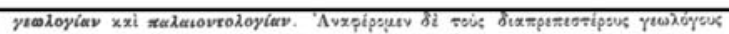

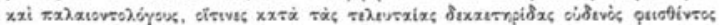

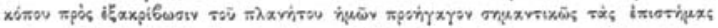
тxirsc, Ch. Lyell, Ch. Darwin, Dana, Geikie, Daubrée, Lapparent, Naumann, Suess, Zirkel, Zittel, Quenstedt, Neumayr, Reyer, Stoppani, Palmieri, xxi

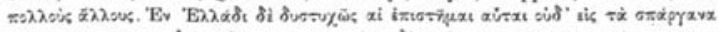

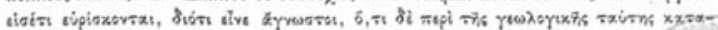

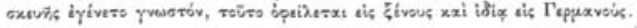

Fig. 2: Details from text book Elements of Geology, 1893.

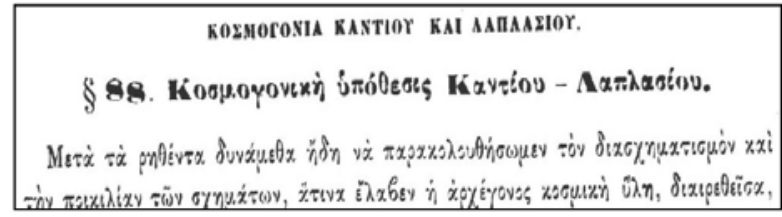

Fig. 3: Details from text book Elements of Geology, 1893.

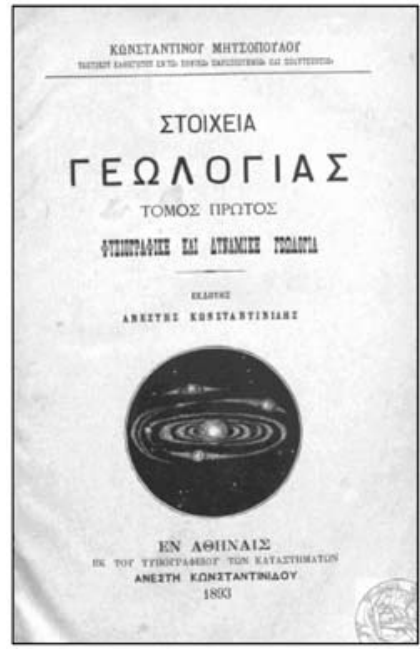

Fig. 4: Elements of Geology, 1893.

ideas to be taught. Mitsopoulos's view on Geology is clear and he does not hesitate to attack to his criticisers.

Both academic books by Con. Mitsopoulos, there are several references to recognized scientists, of that present time, such as Werner, Lyell and Hutton in geological theories about the creation of the earth. At the above book, two of the opposite theories are presented: the theory which proposed rocks are formed from the crystallisation of minerals in the early Earth's oceans (Neptunism) and the theory which claimed that the volcanic activity was the source of rocks on the surface of the Earth with forms that we see nowadays only arising after erosion or other gradual processes (Ploutonism).

Also Con. Mitsopoulos teaches his students including the cosmogony of Kant and Laplace (Fig. 3) for the gradual creation and evolution of planets due to internal forces of the solar system from an

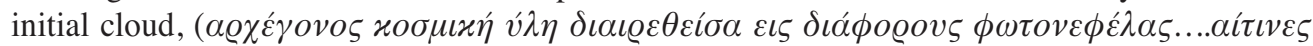
$\delta \iota \alpha \mu \varepsilon \lambda \iota \sigma \theta \varepsilon i \sigma \alpha \iota \varepsilon v \chi \varrho o ́ v \omega \mu \alpha \varkappa \varrho \omega)$ ), the alterations in the earth's magnetism, the theory of Isostasy as well as Darwin's theory of Evolution.

\subsection{Textbooks of Secondary Education}

Anastasios Megas is the author of Elements of Geology and Mineralogy (Fig. 5). He came from the Siatista and was a teacher and scholar. One of his important studies was the "History of the language issue". He studied literature in Athens, and after his graduation, he worked in Secondary Education (1914 - 20) and then, with an introduction by Nikolaos Politis, he was detached as an editor at the Folklore Archive of the Academy of Athens (1920-27). Anastasios Megas was prominent scholar of his time and experienced teacher, without any academic studies.

At the preface of his book, A. Megas does not allow us to conclude whether the book is a translation or not of a foreign textbook. However, the contained figures as well as the contents, reveal that the author was influenced from the academic book "Elements of Geology" by Con. Mitsopoulos.

The first part states that the Geology studies and describes: 


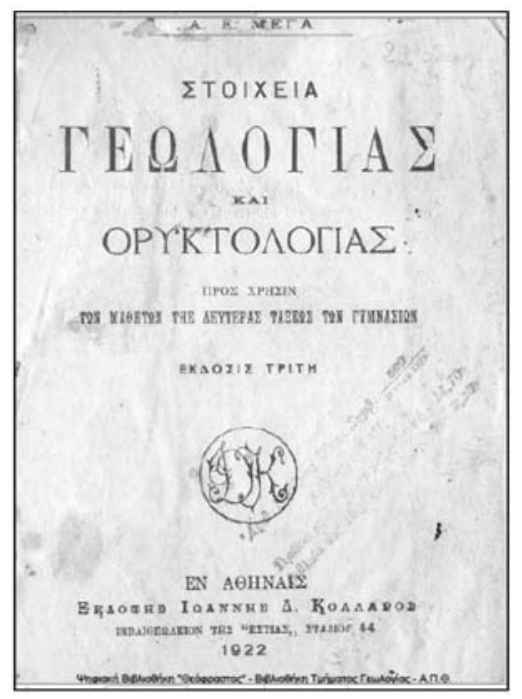

Fig. 5: Elements of Geology and Mineralogy, 1922 .

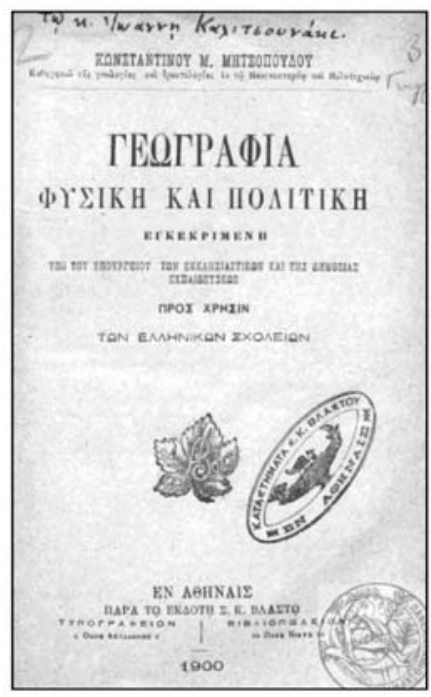

Fig. 6: Text book Physical and Political Geography, 1900.

- The changes that still occur today on Earth, due to the uninterrupted operation of wind and water.

- The occurring phenomena until nowadays and reveal the internal structure of Earth.

- The creation and provision of rocks throughout the lithosphere and the formation of mountains, the plains and the sea.

- The different forms or formations existing on Earth and the evolution of organic beings on it.

Mineralogy is the science that studies and describes, respectively:

- The physical properties of minerals.

- The chemical composition and properties of minerals. The usefulness of each one, and mainly the one of the most useful.

Both belong to the science of physiography, which examines and describes everything on Earth, organic and inorganic matter, and across the Earth, as a natural and celestial body.

Of particular interest is the chapter on Geology in the creation of the Earth, which is far from the present data. The description is vivid; it contains scientific terminology and similar myth-making.

At the chapter on Mineralogy, well developed and detailed data crystallography, the planes of symmetry, the Crystallographic axes, the twins, the cracks and fracture, hardness and durability, specific gravity, the electromagnetic properties. More detailed description of the minerals are of economic and scientific interest for the time, that the: Diamond, graphite, the spontaneous sulfur, gold, silver, copper, iron, pyrite, etc.

A particular example is the book Physical and Political Geography (Fig. 6). by Con. Mitsopoulos. That book was taught in Greek schools, from 1896 to 1901.

Constantine Mitsopoulos followed the footsteps of his uncle, Hercules Mitsopoulos. He studied at the University of Athens, from which he received the first Greek Ph.D in Physics, in 1868, and continued his studies at the University of Freiburg, from where he received the diploma of engi- 


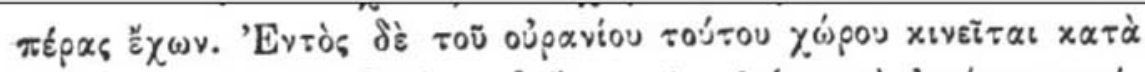

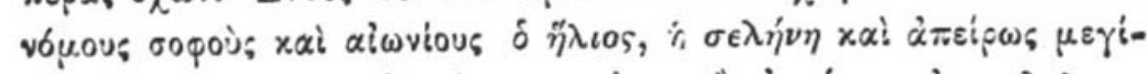

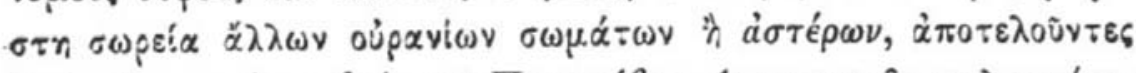

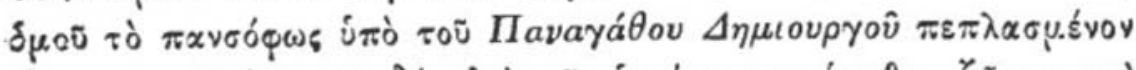
$\sum \dot{u} \mu \pi a \nu . \mathrm{K} \alpha \dot{i}$ '

Fig. 7: Details from text book Physical and Political Geography, 1900.

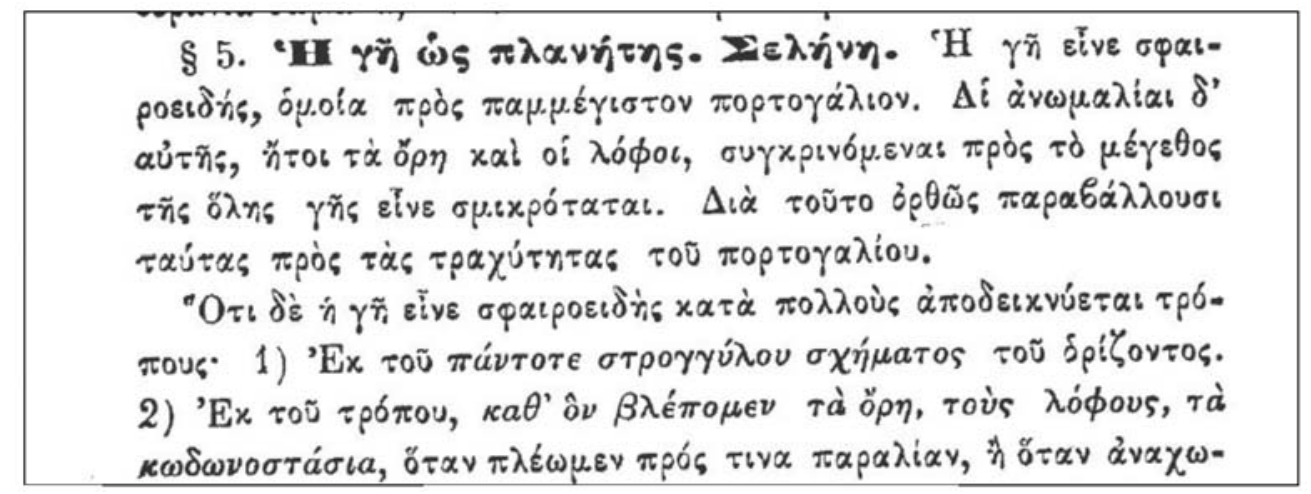

Fig. 8: Details from text book Physical and Political Geography, 1900.

neer metallurgist. In 1875 he was appointed as a Temporary Professor of Geology and Mineralogy at the University of Athens; in 1878 as a Temporary Professor of the same courses at the Polytechnic School and in 1880 he was promoted to Ordinary Professor at the University of Athens. He was elected Dean of the University of Athens (1907) and Director of the Technical University (1902-11). The great contribution of Con. Mitsopoulos was the creation of the Mineralogical Museum, at the University of Athens, which is still used until today for the teaching of students on the subjects of Mineralogy and Geology.

The book is consisted of two parts; "General Geography" (Part A) and "Chorogeografia of five continents". (Part B). The first part, which has a geological content, is divided into four separate chapters, Geonomia, Geophysics, Physiographic, Anthropological Geography and Geography.

In the preface of the above book it is mentioned that the universe is a creation of the Wise God and the mankind is the optimum of God's creation, donated with rationality. (Fig. 7).

A typical passage is the description of the shape of the Earth. The round shape of Earth is proven by empirical thoughts, without any mention on the theory of cosmogony (Fig. 8). Throughout the first part there are no references to scientists, both Greeks and Europeans.

Throughout the book, a narrative structure is followed for general issues with simplified physical geography definitions, using simple definitions, without be mentioned on the formation of mankind and Earth. There are not any references on discreet geologists, despite the fact that Con. Mitsopoulos was aware of their work, as it is obvious at his academic books.

At the same time, the content of University textbooks by Con. Mitsopoulos, is of a different style. 
The inconsistency between high-school and university textbooks written by Con. Mitsopoulos on the origin of mankind and the creation of the universe is obvious. He is considered as a progressive scientist and one of the early and ardent supporters of the Theory on Evolution. Why did he write in another style for secondary education, while his teaching at the University was dominated by contemporary views. Perhaps the answer lays to the needed approval by the Ministry of Education and Church that had to accompany the school textbook Physical Geography and Politics. It is known from the literature that he received severe criticism from Professor of Philosophy S. Lambros and Professor of Mythology and Civil Antiquities N. Politis in 1895, for his, under approval, textbook Geography, which was proposed to be taught at the Greek Schools.

\section{Conclusions-Results}

The content of the textbooks includes knowledge of practical and economic interest (e.g. commercial minerals, exploitable resources). Furthermore, a broad spectrum of subjects such as theories of volcanism, solar activity, and wind and water energy are cited in a descriptive way.

The level and goal of the knowledge on Mineralogy was satisfactory regard to metallic minerals, industrial minerals and valuable stones, since they were relevant to economic and practical applications of Science. On the contrary, the classical taught knowledge on Geology was simply descriptive and, often, the interpretation was conducted using beliefs from mythology and religion.

Essentially, the level of knowledge reflects social and economic needs of the studied period, as well as the need of construction of metal and salt mines.

There is a significant approach to cosmogony in book "Elements of Geology" comparing to the corresponding textbook by the same author, "Physical and Political Geography". In secondary education, the creation of the earth is divine; however, in academic education, the creation and the evolution of Earth is explained by Kant and Laplace.

It is noteworthy that modern scientific concepts, such as the Theory of Evolution, the theory of Isostasy and Cosmogony, arriving on time in Greek books, but only in the University, and therefore the level of geological knowledge in Secondary Education is not consistent with the one of the University.

This conclusion seems inevitable, given that the conservative Greek society of the late 19th century and the beginning of the 20th, the critical theory was not adopted, and contradicted to the wellstructured positions and attitudes of that period.

\section{References}

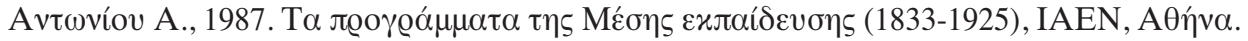

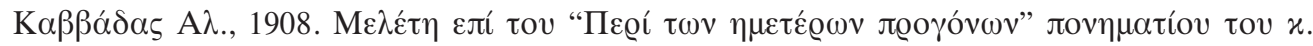

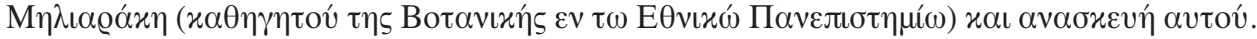

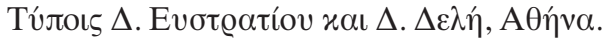

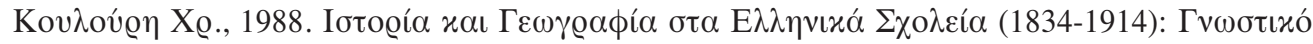

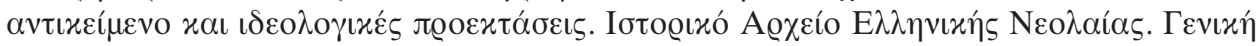

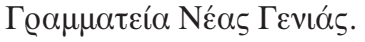

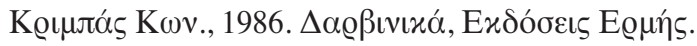

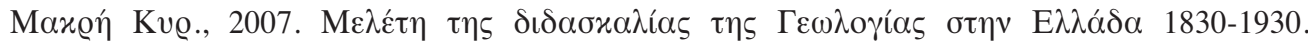




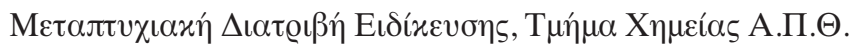

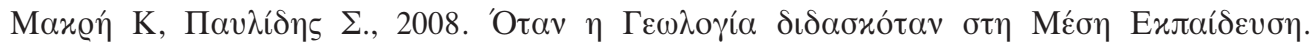

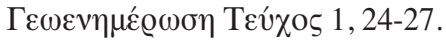

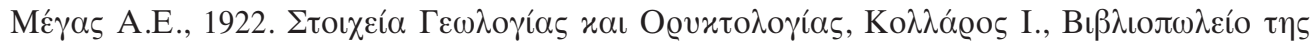
Eơías, A $\theta \dot{v} \alpha$.

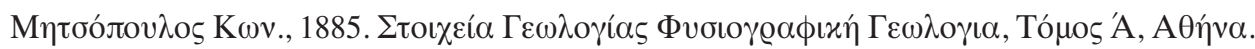

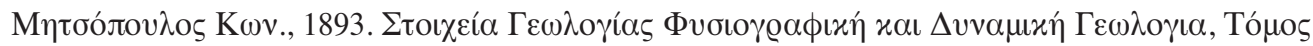
A, А $\theta \dot{v} v \alpha$.

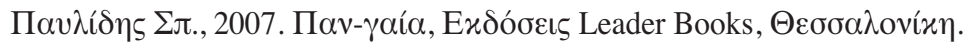

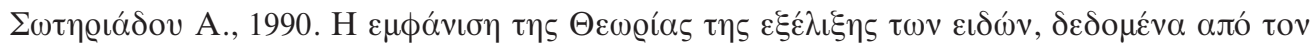

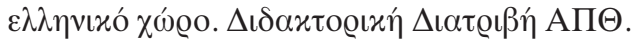

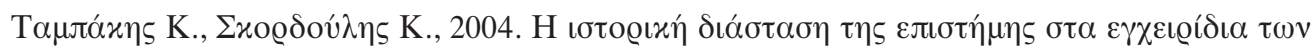

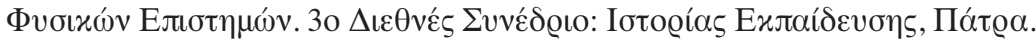

Herbert S., 2005. Charles Darwin, geologist, Cornell University Press.

Delo D. M., 1950. Role of the Earth Sciences in General Education, Science, New Series, Vol. 112, No. 2898.

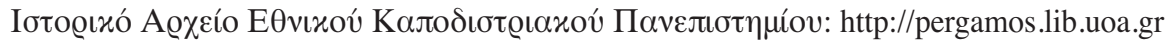

